Rabaska

Revue d'ethnologie de l'Amérique française

\title{
Jean-Julien Bourgault, témoin de son temps, Exposition présentée du 24 novembre 2016 au 3 septembre 2018 au Musée québécois de culture populaire, Trois-Rivières. Commissaire invitée : Nicole Bourgault
}

\section{Jean-François Blanchette}

Volume 15, 2017

URI : https://id.erudit.org/iderudit/1041159ar

DOI : https://doi.org/10.7202/1041159ar

Aller au sommaire du numéro

Éditeur(s)

Société québécoise d'ethnologie

ISSN

1703-7433 (imprimé)

1916-7350 (numérique)

Découvrir la revue

Citer ce compte rendu

Blanchette, J.-F. (2017). Compte rendu de [Jean-Julien Bourgault, témoin de son temps, Exposition présentée du 24 novembre 2016 au 3 septembre 2018 au Musée québécois de culture populaire, Trois-Rivières. Commissaire invitée : Nicole Bourgault]. Rabaska, 15, 305-309. https://doi.org/10.7202/1041159ar d'utilisation que vous pouvez consulter en ligne. 


\section{Jean-Julien Bourgault, témoin de son temps}

Exposition présentée du 24 novembre 2016 au 3 septembre 2018 au Musée québécois de culture populaire, Trois-Rivières.

Commissaire invitée : Nicole Bourgault

Enfin, une exposition sur l'œuvre de Jean-Julien Bourgault (1910-1996) ! Il aura fallu attendre vingt ans après la mort de ce maître sculpteur de SaintJean-Port-Joli pour qu'un musée québécois organise une rétrospective de son œuvre ! Nous devons cette initiative à l'ancien directeur du Musée québécois de culture populaire, Yvon Noël, qui a invité Nicole Bourgault, la fille du sculpteur, à agir en tant que commissaire de cette exposition qui présente près de 80 œuvres de l'artiste, dont les plus anciennes remontent à ses débuts en 1931. On nous le décrit ainsi : « Jean-Julien Bourgault (19101996) fut un sculpteur sur bois prolifique et publiquement prisé. Son parcours riche occupe une position singulière, bien qu'encore peu explorée, dans l'histoire de l'art québécois du $20^{e}$ siècle. [...] Habile et infatigable chroniqueur de son temps, Bourgault enregistra dans des œuvres les récits, légendes et pratiques populaires véhiculés par la tradition orale. Ce faisant, il traduisit dans un style expressionniste, alimenté d'une imagination fertile, le caractère fugace d'une culture et de l'esprit particulier des lieux. »

Deux pièces magnifiques ouvrent cette exposition et invitent à la visiter : À mon drapeau (1951) montre une mère qui explique à ses enfants le drapeau du Québec qu'elle tient sur ses genoux. Jean-Julien voulait ainsi commémorer l'adoption, en 1948, du fleurdelisé par le gouvernement de Maurice Duplessis. Juste derrière, un ange magistral, grandeur d'homme (1960), officialise un évènement, notre visite sans doute. Le choix de ces deux pièces me semble fort judicieux, car elles expriment les éléments symboliques forts de la société de l'époque : la famille, la langue, la patrie et la religion.

L'exposition est organisée en divers thèmes qui aident le visiteur à comprendre les champs d'intérêt du sculpteur. Plusieurs bas-reliefs présentent, de façon humoristique, la vie au quotidien, comme cette œuvre - qu'on pourrait considérer comme un classique de l'art sculptural québécois Le Sermon du curé Fleury (1959) où monsieur le curé s'évertue à prêcher à ses ouailles qui trouvent le temps long, baillent ou s'endorment tout simple- 
ment durant l'homélie. Un autre bas-relief qui m'a impressionné est L'Atelier de Magloire (1961). Cette œuvre nous présente le menuisier Magloire Bourgault avec deux de ses enfants, Jean-Julien et André, qui s'amusent à fabriquer des jouets à ses pieds. Le père est accompagné de son ami le sculpteur au canif Arthur Fournier qui gosse dans un coin. Ce dernier aura une influence marquante sur les frères Bourgault qui devinrent sculpteurs comme lui après avoir brièvement pratiqué le métier de leur père. Pourquoi fallait-il que les enfants se détachent de leur père et se lancent dans une profession au futur incertain à l'époque de la grande crise économique ?

On rappelle à juste titre dans une section de l'exposition, puis dans un montage audiovisuel, l'histoire des trois frères, Médard, Jean-Julien et André, qu'on a surnommés les trois bérets en raison de la coiffure qu'ils portaient. Fils de menuisiers, les circonstances de la vie allaient les amener à développer un métier original et à gagner leur pain en pratiquant une forme d'art issue des traditions populaires et lentement influencée par les normes classiques de l'époque. Jean-Julien et André sont venus rejoindre leur frère aîné Médard à sa requête, car lorsque Médard s'est mis à produire pour le public en 1930, sa popularité fut telle qu'il ne put répondre seul à la demande. C'est ensemble qu'ils développèrent leur habileté à travailler le bois, à sculpter de petites pièces pour les gens intéressés par le travail artisanal et peu à peu pour les touristes que la publicité attira à leur atelier sis dans un hangar modeste derrière la maison de Médard.

Plusieurs des œuvres assemblées pour cette exposition sont petites, mais elles sont raffinées et pleines de détails qu'il faut observer avec minutie afin d'en découvrir toute la vivacité. Des pièces comme L'Essouchage et Le Violoneux, de 1931, montrent une dextérité et un rendu qui n'est pas le propre habituel d'un débutant. Les œuvres que Jean-Julien réalise dès les premières années, entre 1931 et 1933, révèlent déjà une connaissance des formes, une maîtrise des outils et un intérêt marqué pour l'interprétation, souvent enjouée, de la réalité de la vie de chez nous.

Les petites sculptures polychromes - comme Corinne (1931) qui serait la première de l'artiste - pourraient passer inaperçues en raison de leur format. Cette miniature fait partie des nombreuses petites pièces produites comme souvenir pour les touristes. Ces miniatures ont souvent été décriées parce qu'elles étaient faites en série. Pourtant, quand on les examine de près, chacune a sa personnalité. C'est dommage qu'on n'en trouve que très peu dans cette exposition. Elles nous renseigneraient sur les débuts de la sculpture à Saint-Jean-Port-Joli qui a pu progresser grâce aux revenus venant du tourisme. Elles nous informeraient également sur la technique du sculpteur qui s'est fait la main avec ces pièces réalisées avec attention dans ses menus 
détails. Il y aurait beaucoup à dire sur ces pièces sérielles. En effet, n'est-ce pas la production sérielle qui a permis aux artistes modernes, comme Paul Vanier-Beaulieu et Jean-Paul Riopelle, de se faire connaître et de rendre leur art accessible à un plus grand nombre, grâce à leurs lithographies ?

Les Bourgault commencent à sculpter à l'époque où le mouvement occidental connu sous le nom d'Arts and Crafts a encore grande réputation. On veut remettre en valeur ce qui est fait main. Le clergé participe activement à ce mouvement en encourageant les arts. Médard et Jean-Julien reçoivent de nombreuses commandes pour des pièces religieuses - non pas seulement du Québec -, mais aussi de l'Ontario, des Provinces maritimes, de l'Ouest canadien ainsi que des États-Unis. Jean-Julien fonde alors un atelier de production d'ameublement d'églises qu'il opère de 1948 à 1959. Comme on l'indique sur un panneau de l'exposition : « Jean-Julien Bourgault contribua de façon significative au renouveau de l'art religieux, suivant en cela les traces de son frère Médard, connu pour ses crucifix, ses chemins de croix et sa statuaire religieuse (Vierges et saints). Comme lui, il tenta d'adopter une approche personnelle et contemporaine malgré les compromis qu'il dut faire pour satisfaire aux exigences de ses commanditaires. »

Pas moins de 70 églises, cathédrales, chapelles et couvents bénéficieront de l'apport de l'artiste et de ses aides pour les décorer et les meubler. Mentionnons l'église Saint-Charles-Garnier à Québec, la cathédrale Notre-Dame-de-l'Assomption à Moncton (Nouveau-Brunswick) et l'église de Sainte-Thérèse-de-l'Enfant-Jésus à Dieppe (Nouveau-Brunswick). Un écran tactile permet de suivre la feuille de route de Jean-Julien et de découvrir les lieux de culte qu'il a aidé à meubler et à décorer à travers les nombreuses régions du Québec et d'ailleurs.

La créativité ne se fait pas toujours avec l'approbation du public et accepter les commandes ne se fait pas sans heurt pour l'artiste. Jean-Julien sympathise avec son frère aîné Médard qui n'a pas eu la vie facile lorsqu'il désirait s'exprimer librement. Jean-Julien immortalise dans une pièce moderne en bronze, Captivité (1984), les critiques du clergé qui n'acceptait pas l'originalité et la personnalité de Médard dans la création de ses œuvres religieuses. On ne le mentionne pas dans l'exposition, mais Médard désirait exprimer la douleur du Christ, comme dans la tradition espagnole, plutôt que le Christ triomphant que la modernité imposait.

Le langage de Jean-Julien Bourgault va se distinguer nettement de celui de ses frères par le traitement humoristique de ses pièces et par le jeu qu'il développe avec le fantastique. Jean-Julien est conteur et c'est principalement dans le bois qu'il exprime toute sa verve, quoiqu'il utilise le bronze et la pierre, à l'occasion. Contes, légendes et récits fantastiques sont repré- 
sentés dans des rondes-bosses et des bas-reliefs savoureux tels La Chassegalerie et La Coureuse des grèves, imprégnés d'une interprétation toute personnelle.

Maître-sculpteur, il le fut ! Non seulement en raison de la qualité et de la créativité de son œuvre, mais également parce qu'il a formé un nombre imposant d'apprentis tout au long de sa carrière. Son influence fut immense. Dès ses débuts comme sculpteur, Jean-Julien aide des jeunes, habiles ou simplement curieux, à explorer cette forme de créativité et à développer leurs talents. Par la suite, il aura toujours des apprentis qui travailleront et apprendront leur métier avec lui. En 1957, il ouvre une école de sculpture qu'il va diriger jusqu'en 1986. L'impact de son travail et de la formation qu'il a donnée n'a pas encore été évalué à sa juste valeur.

Jean-Julien Bourgault est décédé en 1996, laissant derrière lui sa famille et ses nombreux élèves, mais aussi, dit-on, un carnet de commandes plein. Son œuvre aura été remarquable et abondante. Il aura raconté la vie autour de lui avec beaucoup d'acuité et d'humour. Il aura meublé nos lieux de culte afin que l'action de l'homme soit visible et tangible, là où ce dernier s'agenouille pour adorer son dieu. Il aura été un artiste de son temps, sculptant le laboureur et l'homme religieux que nous étions pour s'adonner plus tard au culte du nu féminin dans toute sa sensualité. C'est d'ailleurs avec un nu d'une grande beauté qu'on termine cette visite, Tourbillon (1981, collection du MQCP).

Les travaux de Jean-Julien Bourgault furent appréciés de nombreux admirateurs tant au Québec qu'au Canada, aux États-Unis et en France. Mais c'est d'abord de l'étranger qu'il reçoit les grands honneurs : l'Ordre national du mérite français dès 1964, l'Ordre du Canada en 1970 et, finalement, il est fait grand officier de l'Ordre national du Québec en 1993.

Cette exposition est une belle initiation à l'œuvre gigantesque de Jean-Julien Bourgault et ses organisateurs méritent nos félicitations. Peutêtre qu'elle éveillera l'attention des muséologues de nos musées nationaux à une exposition majeure sur les frères Bourgault et le mouvement de la sculpture de Saint-Jean-Port-Joli.

JeAn-François Blanchette chercheur associé au Musée canadien de l'histoire 


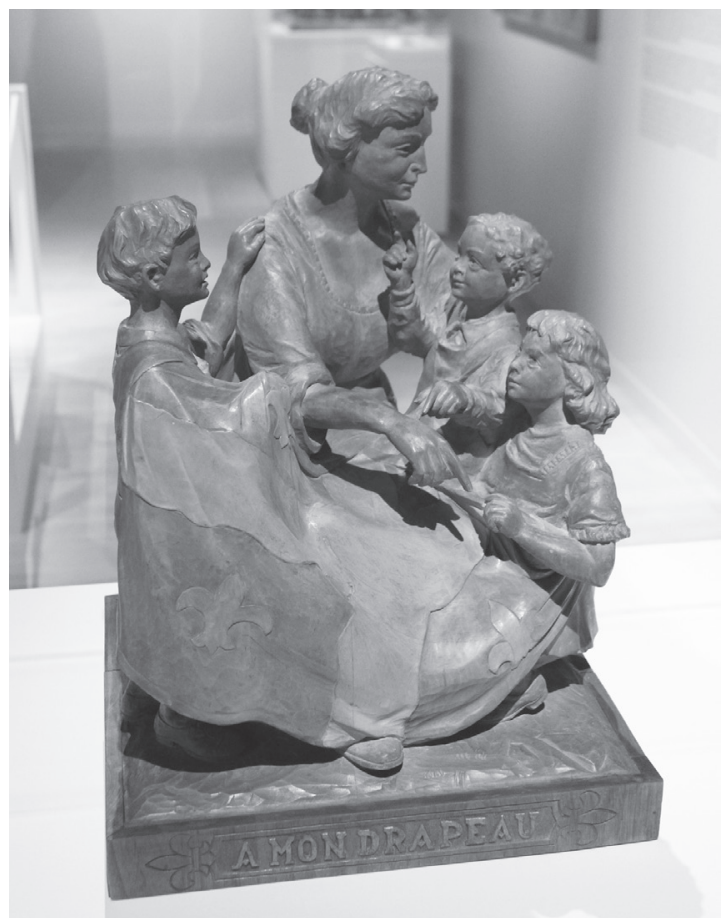

À mon drapeau (1951), d'après un bronze d'Alfred Laliberté (Collection Marie Blanchard)

Photo : Jean-François Blanchette

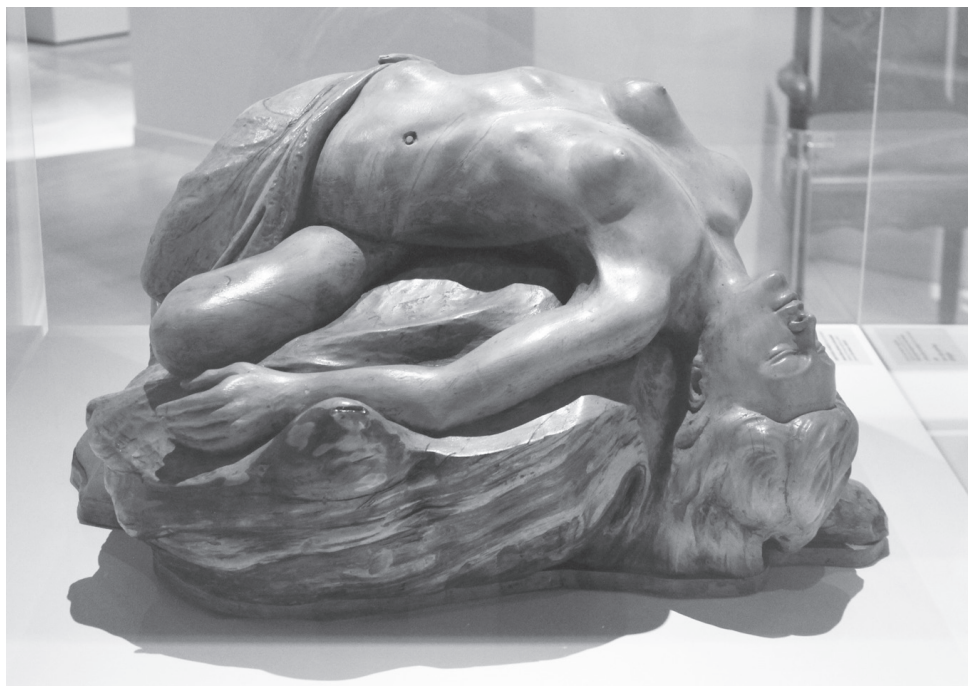

Tourbillon (1981)

(Collection du MQCP)

Photo : Jean-François Blanchette 